\title{
Low Back Pain: Oswestry Low-back Pain Disability and Body Mechanic Practices Among the School Teachers in Tabuk, Saudi Arabia
}

\section{Mathar Mohideen ${ }^{1 *}$, Abdullah Khaled Faifi ${ }^{2}$, Faisal Mohammed Alba- lawi ${ }^{2}$, Khalid Ibrahim Kaabi ${ }^{2}$, Waleed Mansour Gdean Alanze ${ }^{2}$}

${ }^{1}$ Assistant Professor, Department of Nursing, Faculty of Applied Medical Sciences, University of Tabuk, Saudi Arabia

${ }^{2}$ Internship student, Department of Nursing, Faculty of Applied Medical Sciences, University of Tabuk, Saudi Arabia

*Corresponding Author: Mathar Mohideen, Assistant Professor and Program Accreditation Coordinator, Department of Nursing, Faculty of Applied Medical Sciences, University of Tabuk, Saudi Arabia.
Received: August 05, 2021

Published: September 18, 2021

(C) All rights are reserved by Mathar

Mohideen., et al.

\begin{abstract}
Background: Low back pain (LBP) considered to be one of the most common problem among all musculoskeletal conditions, which is very much related with the occupational functioning. Worldwide trend in back pain is escalating. Constant use of "Head -Down" posture, poor posture and improper technique of lifting carrying among the teachers are the common causes that need to be focused in preventing and managing back pain. Safe working practice to be ensured in managing LBP.

Methods: A descriptive cross- sectional study was conducted among the school teachers from the selected schools in Tabuk to identify the low back pain disability level and body mechanic practices by using structured self -administrated questionnaire.

Result: $66.8 \%$ of the study participants had reported back pain. In that majority of the teachers had reported mild and moderate level of back pain, these teachers were able to continue their work. This study had identified significant association with medical illness and previous surgery related to Oswestry Disability Index (ODI) LBP Disability. Only 35.2\% of the teachers had good practices of body mechanics in prevention of back pain. This study also revealed that female gender, marital status and work experience had significantly associated with practices of body mechanics.
\end{abstract}

Conclusion: This study recommends on enhancing the educational activities about body mechanic practices in preventing the LBP.

Keywords: Oswestry Disability Index; Low Back Pain; Body Mechanic Practices

\section{Introduction}

Low back pain is the commonest problem among the all-musculoskeletal problems. As per the estimation of Global Burden of Disease in 2010, LBP is ranked highest in terms of disability. It occurs with high frequency among the general population, $80 \%$ of the people are affected with back pain at any point of their life time [1]. The trend in back pain observed in escalating trend especially among the women and adults which will cause worldwide economic burden [2]. Nearly it affects all the occupational groups: Health Care professional, teachers, lift operator's and layman. Teachers are common occupational group of LBP due to nature of the work that they involve, such as long time standing and sitting and holding neck in forward front posture [3]. Especially the teachers working the with the kindergarten students are involved in lifting and carrying. A study among the female school teachers in $\mathrm{Al}$ -Khobar region had reported $79.1 \%$ of prevalence of musculoskeletal pain disorders. As per the study from Al-Khobar, main sites of pain were lower back (63.8\%) followed by shoulder (45.4\%), neck (42.1\%), leg (40.0\%), wrist (16.2\%), and elbow joint (10.0\%) [4].

Lower back pain (LBP) is the most prevailing musculoskeletal condition that causes disability in low and middle income coun- 
tries [5]. Most of the studies reported high prevalence of back pain among the teachers. Abdel-Salam., et al. [6] from Al-Jouf region reported $65.5 \%$ of back pain among the school teachers. Studies from Dhaka [7], Kuwait [8] and Ethiopia also reported high prevalence of back pain among the school teachers [9]. Various studies have reported different risk factors for the development of back pain, such as aging, female gender, body weight or body mass index, long time standing, work load, previous back injuries, sleep problems and body mechanics $[4,7,8]$.

According to the observation of Mattiuzzi, Lippi and Bovo [2] on the worldwide epidemiologic burden of LBP observed in the last 20 years the current incidence, prevalence and DALYs account for 245.9 million cases/year $\left(15^{\text {th }}\right.$ worldwide cause; $32.4 \%$ cases associated with leg pain), 577.0 million cases ( $15^{\text {th }}$ worldwide cause) and 64.9 million DALYs ( $6^{\text {th }}$ worldwide cause), respectively. The measures observed was over the linear trend, which shows remarkable increase over the 20 years.

The back pain causes severe effect on the physical and psychological wellbeing. It limits the life in socially and in the family. The quality of life also affected with the back pain. LBP results in less productivity, early retirement and less working hours. It causes sick leaves and absenteeism from the work [7,10]. Darwish and Alzuhair [4] had reported more than half (53.3\%) of those suffering pain were considered significant/disabling and were associated with more days of absenteeism.

The teachers are not only involved in class room teaching, they are also involved in preparation of teaching plans, practical session, student's activities and other activities of the school. These activities demand more workload.

Teacher's health is vital for the country's national development. They are also the valuable resource for the socio economic and cultural development of the country. School teachers are susceptible to lower back pain (LBP) due to the nature of their daily work routine which is physically demanding and include common activities that have been identified as important risk factors for lower back pain [11]. There are many occasions school teachers have the possibility of maintaining faulty posture due to long hours of working with computer, corrections of student's papers, long time standing or sitting, which may lead to over usage and improper usage of Musculo skeletal system. Therefore, in this study we are very much interested to study the low back pain disability and the body mechanics practices. There are no studies related low back pain among the school teachers from Tabuk city. This study will great insight into the health of the teachers. The Aim of this study was to identify the prevalence and associated risk factors related to development of LBP among school teachers in Tabuk city.

\section{Objectives}

- To identify the Low back pain disability among the school teachers.

- To find the association between the low back pain disability level and demographic variables.

- To assess the body mechanics practices among the school teachers.

- To identify the association between the body mechanics practices and demographic variables.

- $\quad$ To identify the correlation between the low back pain and the practice of body mechanic practices among the school teachers.

\section{Study design and setting}

A descriptive cross- sectional study was conducted among the school teachers from the selected schools to study the low back pain, disability level and body mechanic practices by using structured self -administrated questionnaire. This study was conducted among the teachers from the selected schools from Tabuk, Saudi Arabia from Jan 2020 to April 2020.

\section{Study participants, sample and sampling technique}

The teachers of the selected schools participated in the study based on the inclusion and exclusion criteria. Convenient sampling technique was used to select the schools. Simple random sampling was used to select the teachers from the selected school. Overall, 320 teachers from the school were invited to participate in the study. 214 teachers experienced low back pain in any point of time is past 12 months.

The sample was chosen based on the following criteria.

\section{Inclusion criteria}

- The full-time teachers who were willing to participate in the study

- The participants who work in the profession for at least a year. 


\section{Exclusion criteria}

The teachers with the Musculoskeletal and neurological problems and deformities, suffering from any Systemic illness or any other chronic illness, using analgesics, had recent fractures, hip pathology and surgeries and pregnancy are excluded from the study.

The teachers on leave or absent during the study period are also excluded from the study.

\section{Data collection procedure}

In the first step of the study ethical approval and Institutional permission was taken.

In the second step -The teachers were explained about the objectives of the study and necessity of the study among the school teachers. An informed consent was taken from all the participants. The participants were included, all those who experienced low back pain at any time during last 12 months. The study participants were recruited based on the inclusion and exclusion criteria.

In the third step -The data were gathered with the self-administered questionnaire with the following sections:

- $\quad$ Part 1 Demographic data age, gender, weight, height, educational status, number of children, smoking habits, marital status, and years of teaching experience etc.

- $\quad$ Part 2 Oswestry low-back pain Disability Index (ODI).

The Oswestry low-back pain Disability Index (ODI), a self-administered questionnaire, developed by Jones and Hunt, in England, was used to measure disability. It contains 10 different areas concerning with the intensity of pain such as walking, standing, social life, etc. Each area has 6 statements, which is scored 0-5. 0 indicates least disability and 5 indicates severe disability. Total score for ODI ranges from 0 to 100 . Scores are added and the final score is expressed as "\% disability." Grading of the disability is described as (1) minimal disability (0\%-20\%), when a patient can cope with most living activities; (2) moderate disability (21\%-40\%), when patient may be disabled from work and reports more pain and difficulty with sitting, lifting, and standing; (3) severe disability: (41\%-60\%), when pain remains the main problem; (4) crippled (61\%-80\%), when pain affects all aspects of the patient's life; and (5) bedbound or exaggerating (81\%-100\%) [12,13].
Part 3 Body mechanics practices

Body mechanics practices were assessed by using the principles of body mechanics. This section includes 8 items with yes or no response.

\section{Ethical clearance}

The study was approved by the departmental ethical committee. The proposal was submitted the school authorities and permission was obtained. Participants were assured with privacy and confidentiality of the data by the investigators. Consent was taken before the study.

\section{Statistical analysis}

The Statistical Package for The Social Sciences (SPSS for Windows) was used to analyze the data. Means, standard deviations (SD) were used to calculate the ODI and body mechanic practices. Frequency and percentage were used for the demo-graphic variables. Pearson's correlation coefficient was used to find the relationship between the low back ODI scores and body mechanic practices. Chi-square test was performed to find the association between the demographic variables and ODI scores of the teachers and practices.

\section{Results}

Overall, 214 teachers had reported LBP. Nearly half of the study participants between the age group of 31-40 years (48.1\%), more than half of them female (56\%), most of them are married (73.8\%), $34.6 \%$ of them with $1-3$ children, most of the school teachers $(83.3 \%)$ had bachelor's degree, four fifth of them $(79.1 \%)$ were nonsmokers, only $15.4 \%$ of the teachers are having experience more than 20 years, only $46.3 \%$ of them exercise regularly, $6.1 \%$ of them had history of back surgeries and $22.9 \%$ of them are with the other medical illness, Most of the participants in the study always standing for long time (68.7\%).

$68.7 \%$ of the teachers were working with always standing during work hours. $41.1 \%$ of the participants had pre obesity. (28\%) of them had normal BMI. Nearly one fifth of them had Obesity-I (21\%). (9.4\%) of the them had obesity-II. 0.5 percent of the study participants had underweight (Table 1). 


\begin{tabular}{|c|c|c|}
\hline Demographic variables & Frequency & Percentage \\
\hline \multicolumn{3}{|l|}{ 1.Age (in years): } \\
\hline$<30$ years & 40 & 18.7 \\
\hline $31-40$ years & 103 & 48.1 \\
\hline $41-50$ years & 53 & 24.8 \\
\hline 50 and above & 18 & 8.4 \\
\hline \multicolumn{3}{|l|}{ 2.Sex : } \\
\hline Male & 120 & 56.1 \\
\hline Female & 94 & 43.9 \\
\hline \multicolumn{3}{|l|}{ 3.Marital status : } \\
\hline Single & 46 & 21.5 \\
\hline Married & 158 & 73.8 \\
\hline Divorced & 10 & 4.7 \\
\hline \multicolumn{3}{|l|}{ 4.No of Children: } \\
\hline Nil & 98 & 45.8 \\
\hline $1-3$ & 74 & 34.6 \\
\hline $4-6$ & 38 & 17.8 \\
\hline $7-9$ & 2 & 0.9 \\
\hline 10 and above & 2 & 0.9 \\
\hline \multicolumn{3}{|l|}{ 5.Educational qualification : } \\
\hline Diploma & 14 & 6.5 \\
\hline Bachelor's degree & 178 & 83.3 \\
\hline Master degree & 17 & 7.9 \\
\hline PHD & 5 & 2.3 \\
\hline \multicolumn{3}{|l|}{ 6.Smoking habit: } \\
\hline Yes & 44 & 20.5 \\
\hline No & 170 & 79.5 \\
\hline \multicolumn{3}{|l|}{ 7.Working experience : } \\
\hline$<10$ years & 88 & 41.1 \\
\hline 11-20 years & 93 & 43.5 \\
\hline$>20$ years & 33 & 15.4 \\
\hline \multicolumn{3}{|l|}{ 8.Exercise Regularly : } \\
\hline Yes & 99 & 46.3 \\
\hline No & 115 & 53.7 \\
\hline \multicolumn{2}{|l|}{ 9.Job is related with prolonged } & 68.7 \\
\hline Always & 65 & 30.4 \\
\hline Some times & 2 & 0.9 \\
\hline Rarely & & \\
\hline \multicolumn{3}{|l|}{ 10.Suffer from any medical illness } \\
\hline Yes & 49 & 22.9 \\
\hline No & 165 & 77.1 \\
\hline
\end{tabular}

\begin{tabular}{|c|c|c|}
\hline 11.Undergo any surgery on Back & 13 & 6.1 \\
Yes & 201 & 93.9 \\
No & & \\
12.BMI : & 1 & 0.5 \\
Underweight & 60 & 28 \\
Normal & 88 & 41.1 \\
Pre obesity & 45 & 21 \\
Obesity -I & 20 & 9.4 \\
Obesity-II & \\
\hline
\end{tabular}

Table 1: Frequency and percentage wise distribution school teachers based on their demographic data. $(n=214)$.

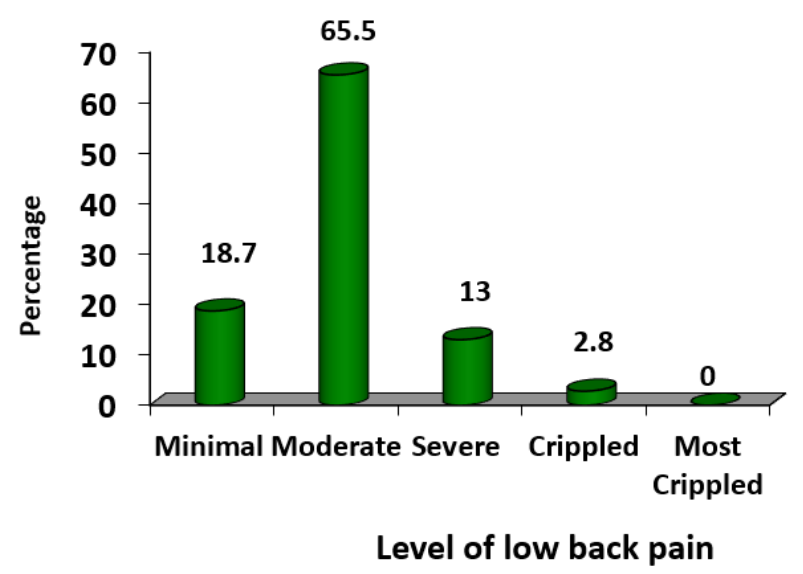

Figure 1: Distribution of school teachers based on Oswestry Disability Index (ODI) scores.

Most of the study participants had reported moderate level of back pain $65.5 \%$. Nearly one fifth $(18.7 \%)$ of the study participants had reported minimal back pain. 13 per cent of them had reported severe back pain, only 2.8 percent crippled and none of them reported most crippled. (Figure 1) The mean score of Oswestry lowback pain Disability Index (ODI) was 13.90 with SD-4.61. Most of the teachers with minimal and moderate scores on ODI was noticed.

More than one third of the school teachers had reported good body mechanic practices (35.2\%), one third of the school teachers 


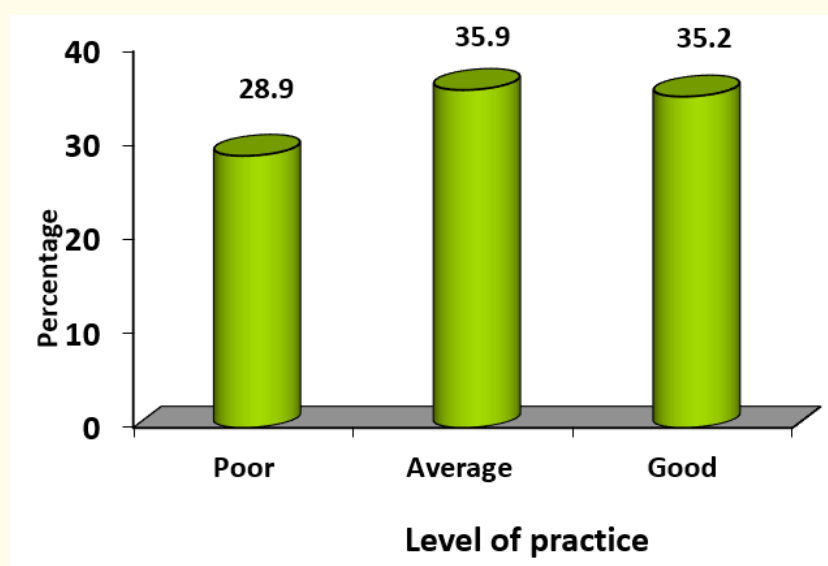

Figure 2: Distribution of school teachers based on reported body mechanic practices.

had reported average body mechanic practices (35.9\%), 28.9\% of the study participants had reported poor body mechanic practices related to body mechanics (Figure 2). The mean scores on the body mechanic practices were 5.38, SD-2.18. The minimum score was o and maximum score was 8. Results indicate most of teachers follow average body mechanic practices.

The teachers who had medical illness $(\chi 2=20.43, \mathrm{P}<0.001)$ and who had undergone surgery previously $(\chi 2=8.23, \mathrm{p}<0.05)$ were shown significant association with the level of low back disability. Other variables were not significant. The following demographic variables were associated with the level of practicing body mechanics. Sex $(\chi 2=7.36, \mathrm{p}<0.05))$, Marital status $(\chi 2=13.09, \mathrm{P}<$ $0.05)$ and working experience $(\chi 2=10.74, \mathrm{P}<0.05)$. Male teachers had good practices than the female teachers.

Weak negative correlation was observed between the Oswestry low-back pain Disability Index (ODI) and body mechanic practices among the teachers $(r=-0.199, p=0.003)$ (Figure 3 ).

\section{Discussion}

In this study $66.8 \%$ of teachers who reported back pain were included to identify the disability level and body mechanic practices. Similarly study findings observed in the study from western Kenya, about $64.98 \%$ of school teachers reported back pain by Elias, Downing and Mwangi [14] and also from a study from Bo-

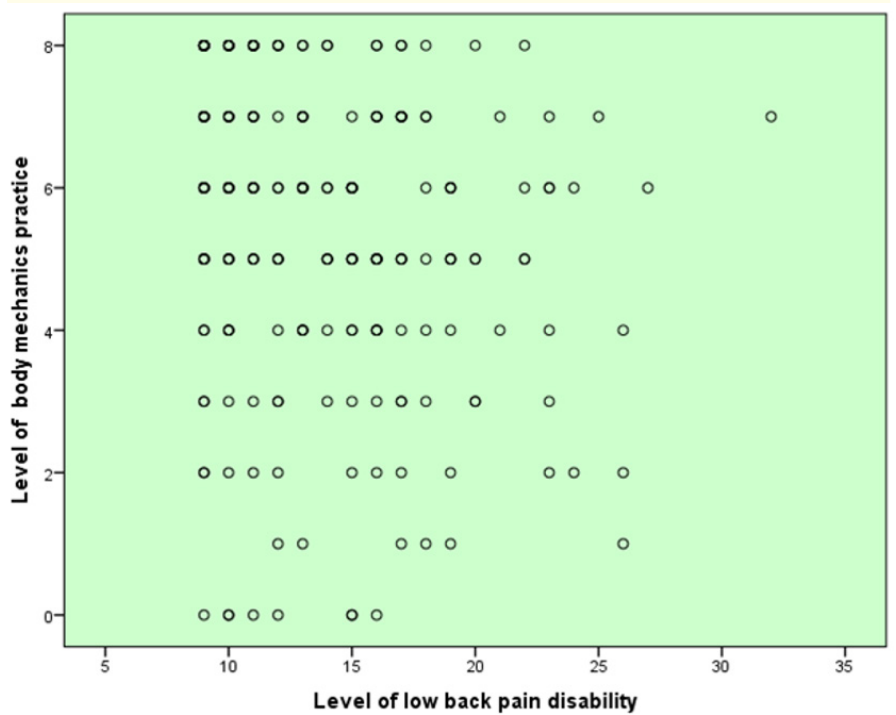

Figure 3: Co-relation between low back pain and the practice of body mechanics among the school teachers in Tabuk.

tswana had reported 67.1\% teachers with back pain [15]. Similarly, $\mathrm{Al}$-Khobar region had reported $63.8 \%$ of LBP among the school teachers [4].

Among the study participants, most of the study participants had reported moderate level of back pain(65.5\%). Nearly one fifth $(18.7 \%)$ of the study participants had reported minimal back pain. This study reported that higher number of school teachers suffering from back pain in some form mostly minimal to moderate level. Similarly, a study from Botswana also reported mostly minimal to moderate level of back pain [15] and also study from western Kenya reported most of the teachers with minimal and very low proportion of teachers had severe disability [14].

In this study Age, gender, educational qualification, marital status, number of children, working experience and BMI are not significantly associated with the LBP. However in most of the studies LBP have associated with the age and female gender. A study among school teachers in Al-Khobar region had showed significant relationship with type of school, age, weight, number of children, shoe type, teaching years, and working daily hours [4]. A study from China had reported no significance with the age and back pain [3]. A study from west Kenya found the low back pain highly 
significant with the female teachers. In their study female teachers had experienced back pain more than 1.5 times than men. This study also revealed that lack of support from the supervisors also significant with low back pain [14]. Studies from Botswana and Ethiopia also reported high significant of female teachers and back pain. In this study, the teachers who had medical illness $(20.43, \mathrm{P}$ $<0.001)$ and who had undergone surgery previously $(8.23,0.041)$ were shown significant association with the level of low back disability. In most of the studies, these factors were not studied. A study from Botswana school teachers [15] and Saudi Arabia [16] had reported no association between the back pain and BMI. In a study from Aljouf region, Significant predictors of disabling musculoskeletal pain among the school teachers were age more than 40 years, not practicing exercise, more than ten years of teaching, and non-comfortableness of school furniture [6]. This study revealed that female gender ( $7.36 \mathrm{df}=2,0.025)$ ), Marital status and working experience had significantly associated with the practices of body mechanics which contributes to LBP.

In this study More than one third of the school teachers had reported good practices (35.2\%), one third of the school teachers had reported average practices (35.9\%), 28.9\% of the study participants had reported poor practices related to body mechanics. Half of the participants had reported poor weight managing practices. Mostly the teachers reported long standing and sitting. A study from China also had reported sitting more than 3 hours also significant with the low back pain [3]. Similarly, Bener, Dafeeah, Alnaqbi from Qatar revealed that prolonged sitting, standing and uncomfortable furniture was positively associated with LBP [17].

Weak correlation identified between the disability level and body mechanic practices. The teachers with good body mechanic practices with low disability scores were observed.

\section{Recommendations}

This study recommends the upcoming researcher who wanted to investigate the prevalence of LBP among teacher to include various academic groups such as university teachers and kindergarten teachers. Detailed study with large number of samples is necessary to identify the contributing factors to find the easy management. Comparative studies between the regions in Saudi Arabia and Experimental studies on controlling and preventing back pain and body mechanics will greatly contribute in the management of back pain.

\section{Conclusion}

In this study majority of the teachers had mild and moderate level of back pain. These teachers were able to continue their work and were not required for any health facility management. This study had identified significant association with medical illness and previous surgery related to Oswestry Disability Index (ODI) LBP Disability. Only $35.2 \%$ of the teachers had good practices of body mechanics in prevention of back pain. This study highly recommends on the necessity of preventive management program among the school teachers. There should support system and different strategies to be implemented in the teaching methods regards to preventing back pain. Organizing a teaching program on body mechanic practices are necessary to prevent and manage low back pain.

\section{Bibliography}

1. Ehrlich GE. "Low back pain. World Health Organization". Bulletin of the World Health Organization 81 (2003): 671-676.

2. Mattiuzzi Camilla, et al. "Current Epidemiology of Low Back Pain". Journal of Hospital Management and Health Policy 4 (2020): 15-15.

3. Yue Pengying., et al. "Neck/Shoulder Pain and Low Back Pain among School Teachers in China, Prevalence and Risk Factors". BMC Public Health 12.1 (2012).

4. Darwish Magdy A and Shatha Z Al-Zuhair. "Musculoskeletal Pain Disorders among Secondary School Saudi Female Teachers". Pain Research and Treatment 2013 (2013): 1-7.

5. Louw Quinette A., et al. "The Prevalence of Low Back Pain in AFRICA: A Systematic Review". BMC Musculoskeletal Disorders 8.1 (2007).

6. Abdel-Salam Doaa M., et al. "Musculoskeletal Pain and Its Correlates among Secondary SCHOOL Female Teachers in Aljouf Region, Saudi Arabia". Journal of Public Health 29.2 2019): 303-310.

7. Akter Joyonty., et al. "Prevalence and Factors Associated with Low Back Pain among School Teachers Residing in Northern Dhaka City". MOJ Orthopedics and amp; Rheumatology 10.5 (2018).

8. MA Al-Rowayeh., et al. "Low back pain among high school teachers in Kuwait: Prevalence, risk factors and level of disability". KMJ-Kuwait Medical Journal 49.4 (2017): 318-326.

Citation: Mathar Mohideen., et al. "Low Back Pain: Oswestry Low-back Pain Disability and Body Mechanic Practices Among the School Teachers in Tabuk, Saudi Arabia". Acta Scientific Orthopaedics 4.10 (2021): 60-66. 
9. Kebede Aregawi., et al. "Low Back Pain and Associated Factors among Primary School Teachers in MEKELE City, North ETHIOPIA: A Cross-Sectional Study". Occupational Therapy International 2019 (2019): 1-8.

10. Sandmark H. "Musculoskeletal Dysfunction in Physical Education Teachers". Occupational and Environmental Medicine 57.10 (2000): 673-677.

11. Padula Rosimeire Simprini., et al. "Low Back Pain Disability and Stay at Work: Contradiction or Necessity?" Work 41 (2012): 2417-2419.

12. Fairbank Jeremy C and Paul B Pynsent. "The Oswestry Disability Index". Spine 25.22 (2000): 2940-2953.

13. Algarni AS., et al. "Validation of an Arabic Version of the Oswestry Index in Saudi Arabia". Annals of Physical and Rehabilitation Medicine 57.9-10 (2014): 653-663.

14. Elias Hussein E., et al. "Low Back Pain among Primary School Teachers in Rural Kenya: Prevalence and Contributing Factors". African Journal of Primary Health Care \&amp; Family Medicine 11.1 (2019).

15. Erick Patience N and Derek R Smith. "Low Back Pain among School Teachers in Botswana, Prevalence and Risk Factors". BMC Musculoskeletal Disorders 15.1 (2014).

16. Abdulmonem A., et al. "The prevalence of musculoskeletal pain and its associated factors among female Saudi school teachers". Pakistan Journal of Medical Sciences 30.6 (2014): 1191-1196.

17. Bener A., et al. "Prevalence and correlates of low back pain in primary care: what are the contributing factors in a rapidly developing country". Asian Spine Journal 8.3 (2014): 227-236.

\section{Volume 5 Issue 10 October 2021}

(C) All rights are reserved by Mathar Mohideen., et al.

Citation: Mathar Mohideen., et al. "Low Back Pain: Oswestry Low-back Pain Disability and Body Mechanic Practices Among the School Teachers in Tabuk, Saudi Arabia". Acta Scientific Orthopaedics 4.10 (2021): 60-66. 